\title{
New insights into atherosclerotic plaque rupture
}

\author{
D M Braganza, M R Bennett
}

Coronary artery atherosclerosis is the major cause of mortality and morbidity in the industrialised world. Progressive narrowing of coronary arteries causes angina. However, it is rupture of the plaque that causes the catastrophic consequences of atherosclerosis, such as myocardial infarction. Recent work has identified that the stability of the plaque rather than its absolute size determines the likelihood of rupture, making a change in plaque composition rather than plaque regression a worthwhile clinical goal. This review summarises recent advances in the understanding of plaque rupture, and identifies areas in which new therapies may be directed.

\section{The vulnerable plaque}

Myocardial infarction and unstable angina are caused by rupture or erosion of an atherosclerotic plaque, with subsequent thrombus formation and occlusion of the artery. The plaque that causes a patient's heart attack is not necessarily the one that is identified at angiography. Cardiologists conventionally describe coronary artery stenoses as significant when they occupy $>50 \%$ of the arterial lumen, that is when they become flow limiting. However, a series of postmortem and angiographic studies has identified that nearly $70 \%$ of myocardial infarctions are caused by rupture of plaques that cause $<50 \%$ stenosis, and that $<20 \%$ are caused by lesions that are $>70 \%$ stenotic (reviewed by Falk et $a l^{1}$ ). Thus, the quality of the plaque rather than the quantity determines the clinical consequences of atherosclerosis.

The atherosclerotic plaque consists of a collection of vascular smooth muscle cells (VSMCs) and inflammatory cells (macrophages and $\mathrm{T}$ lymphocytes), with both intracellular and extracellular lipid. However, the stability of the plaque depends upon the VSMC content of the plaque, as only these cells are capable of synthesising the structurally important collagens I and III. In contrast, inflammatory cells (particularly macrophages) release matrix metalloproteinases (MMPs) which degrade collagen and extracellular matrix, potentially weakening the plaque. In recent years, the characteristics of plaques that are predisposed to rupture have been identified. Vulnerable plaques have high lipid and inflammatory cell contents, increased MMP activity, and a low content of VSMCs and collagen. ${ }^{2}$ VSMC apoptosis (cell death) is also increased in unstable compared with stable plaques, ${ }^{3}$ suggesting that VSMC apoptosis may directly promote plaque instability.

\section{Vascular smooth muscle cells in the atherosclerotic plaque}

VSMCs in the atherosclerotic plaque have been traditionally viewed as responsible for the generation of the lesion, and therefore are an undesirable consequence of the atherosclerotic process. In contrast, more recent reviews have emphasised the role of VSMCs in maintaining the integrity of the plaque, ${ }^{45}$ and suggested that VSMC proliferation may be beneficial to plaque stability. Indeed, fatal events in atherosclerosis are due to rupture of the thinnest part of the fibrous cap region, ${ }^{6}$ that is synthesised almost exclusively by VSMCs, and rupture sites are characterised by relatively low density of VSMCs. ${ }^{2}$ The fibrous cap region undergoes continuous damage followed by subsequent repair in a complex atherosclerotic plaque. Most of these episodes of erosion and repair are silent. However, any process that prevents VSMC repair of the cap is potentially dangerous, such as failure to undergo cell proliferation or a susceptibility to undergo apoptosis.

\section{Evidence for cell senescence in atherosclerosis}

VSMCs in atherosclerotic plaques have low levels of cell proliferation. ${ }^{78}$ Extensive characterisation of lesion development has shown that cell proliferation is low in early atherosclerosis (fatty streak, Stary type I lesion stage), peaks in the intermediate lesions (Stary type II-IV), and declines in advanced fibroproliferative, complicated plaques (Stary type V lesions). ${ }^{9}$ Although cell proliferation increases after plaque rupture, the cells that proliferate are macrophages, not VSMCs. ${ }^{9}$ This indicates that VSMC proliferation is reduced as plaques age, and does not increase after plaque rupture. The vigorous response to angioplasty/ stenting does not imply that it is the fibrous cap/intimal cells that have responded. Evidence from animal studies implies that the reparative response in restenosis may be due to deep medial injury, with subsequent migration of medial or adventitial cells that still possess the capacity to proliferate. ${ }^{10}$

Cell proliferation in the advanced plaque is regulated by countervailing influences, such as the presence of growth factors that bind to cognate receptors on plaque VSMCs, and the restraining influences of cell matrix (see Newby and Zalltsman for review ${ }^{11}$ ). Advanced atherosclerotic plaques are characterised by high level expression of growth factors for VSMCs such as platelet derived growth factor and insulin like growth factor- $1,{ }^{12}{ }^{13}$ and rupture sites show evidence of matrix breakdown. Under these circumstances, the failure of VSMCs to proliferate is therefore not due to a lack of mitogenic stimulation or the restraint of matrix alone. These observations suggest that plaque intimal VSMCs have an intrinsic defect in their capacity to proliferate.

In vitro studies on plaque and medial VSMCs have confirmed that such a defect 
exists. Plaque VSMCs show reduced cell proliferation rates, increased population doubling times, and earlier failure to proliferate (senescence) than medial VSMCs. ${ }^{14}{ }^{15}$ This defect is not corrected by supplementation of growth factors ${ }^{14}$ and clearly matrix restraint is not involved in dispersed cells. Plaque VSMCs in vitro and in vivo also demonstrate morphological appearances of senescent cells, such as a stellate or flat appearance. ${ }^{16}{ }^{17}$ This phenotype of plaque VSMCs implies that they have undergone cell senescence, possibly due to an exhaustion of an intrinsic, defined number of cumulative cell divisions. Plaques have been shown to arise from expansion of a clone of pre-existent VSMCs, or migration from a clone of underlying medial VSMCs. ${ }^{18}$ Proliferation under these circumstances is selective rather that multifocal, a situation also seen in proliferation after arterial injury, when intima is formed by proliferation of small number of cells many times, rather than a few divisions in all cells that migrate. Thus, it is highly likely that the intimal VSMCs within the fibrous cap of plaques are senescent.

\section{Evidence for vascular smooth muscle cell} death in atherosclerosis

Increasing evidence indicates that apoptosis of VSMCs promotes plaque instability. Thus, higher levels of VSMC apoptosis are seen in plaques compared with normal vessels, ${ }^{19-21}$ and in unstable compared with stable plaques. ${ }^{3}$ In addition, plaque derived VSMCs are intrinsically sensitive to apoptosis mediated by a variety of mechanisms. ${ }^{15}$ More recent work has found that human monocyte/macrophages are potent inducers of apoptosis of human VSMCs in coculture. ${ }^{22}$ Apoptosis requires direct cellcell contact, and is mediated by a number of different pathways, including the death receptors Fas and tumour necrosis factor- $\alpha$ (TNF$\alpha$ ), and by nitric oxide. Apoptosis also requires priming of VSMCs by upregulation of surface Fas and TNF-R $1 .^{23}$

Apoptosis of VSMCs and inflammatory cells in atherosclerosis may also have other important sequelae. In contrast to the prevailing notion that apoptotic deaths are effectively silent (that is, they do not elicit an immune response) a number of deleterious effects of apoptotic cells within the vasculature have emerged. First, the exposure of phosphatidylserine on the surface of apoptotic cells provides a potent substrate for the generation of thrombin and activation of the coagulation cascade. $^{24}{ }^{25}$ Apoptotic cells also release membrane bound microparticles into the circulation, which remain procoagulant and are increased in patients with unstable versus stable coronary syndromes. ${ }^{26}{ }^{27}$ Although apoptotic cells are not the only source of circulating microparticles, such microparticles may contribute to the increased procoagulant state in these syndromes, and account for almost all of the tissue factor activity present in plaque extracts.
Role of inflammation in plaque rupture Monocyte/macrophages are present in atherosclerotic plaques from the earliest lesions to complicated, ruptured plaques. Activated macrophages infiltrate the fibrous cap, especially at the shoulder region where the cap joins the more normal vessel wall, ${ }^{28}{ }^{29}$ a particular site for plaque rupture. ${ }^{30}$ Macrophage infiltration of the fibrous cap is found in $>75 \%$ of ruptured plaques, and occurs more commonly in the culprit lesions of unstable versus stable angina patients. ${ }^{31}$ Macrophage infiltration has a number of deleterious effects, all of which reduce the tensile strength of the cap, directly promoting plaque rupture. ${ }^{29}$

First, macrophages within the plaque are scavenging cells that accumulate lipid to become foam cells. Macrophage and extracellular lipid accumulation expands the lipid core of lesions, destroying intimal tissue and fibrous caps, ${ }^{32}$ and also results in progressive tissue destruction of the media and elastic lamina below the core, ${ }^{33}{ }^{34}$ Second, macrophages can degrade extracellular matrix by secreting a variety of MMPs (collagenases, gelatinases, stromolysins). ${ }^{35}{ }^{36}$ Cytokines released by macrophages and $T$ lymphocytes can stimulate MMP expression in both macrophages and VSMCs, ${ }^{37-41}$ and increased expression and activity of MMPs has been demonstrated in vulnerable regions. ${ }^{35}$ Furthermore, macrophages have been directly demonstrated to cause collagen breakdown in plaques. ${ }^{42}$ Finally, activated macrophages can directly induce VSMC apoptosis, thus further reducing the ability of the fibrous cap to repair itself and synthesise collagen.

\section{Improving plaque stability-the new therapeutic aim}

Until recently, the conventional view of atherosclerosis has been of an indolent lesion, gradually accumulating cells and lipid and eventually stenosing the vessel to cause symptoms. In contrast, evidence accumulated over the last 15 years has emphasised that the plaque is a dynamic structure, undergoing a continual cycle of erosion and repair. Thus, postmortem studies demonstrate that plaque ruptures and erosions are frequent phenomena, most of which are clinically silent. The cycle of erosion and repair is also responsible for plaque growth. Ruptures that cause thrombosis that are insufficient to cause lumenal occlusion heal by organisation of the thrombus, via migration and division of VSMCs. The reorganised thrombus is then incorporated into the growing plaque, further enlarging the lesions. Thus, plaques demonstrate evidence of repeated episodes of erosion and healing, ${ }^{43}$ and plaque growth is demonstrated clinically by the sudden appearance of "new" lesions on coronary angiograms. The silent nature of plaque growth means that by the time most patients present with coronary artery disease, the plaques may be very advanced.

From the above discussion, it can be seen that interruption of the cycle of erosion and repair will not only inhibit plaque rupture with its often fatal sequelae, but also inhibit plaque 


\section{Key points}

- Myocardial infarction is caused mostly by plaques that cause $<50 \%$ stenosis

- Statins cause profound changes in plaque composition and reduce clinical events, with little change in plaque size

- Statins reduce inflammatory cell content and lipid content of experimental atherosclerotic plaques

- Statins increase vascular smooth muscle cell and collagen content of experimental atherosclerotic plaques

\section{Vulnerable plaques contain:}

- High lipid contents

- High inflammatory cell contents

- Low vascular smooth muscle cell and collagen contents

- Higher levels of vascular smooth muscle cell apoptosis

growth and progression. The vulnerable plaque contains large amounts of lipid, a high proportion of activated inflammatory cells, high levels of expression of MMPs, low VSMC contents and high levels of VSMC apoptosis. The ideal drug to stabilise plaques would therefore reduce lipid and inflammatory cell contents, reduce MMP activity, and increase VSMC and collagen contents of plaques.

In recent years primary and secondary prevention trials have unequivocally proved that reduction in cholesterol using 3-hydroxy3-methylglutaryl coenzyme A (HMGCoA) reductase inhibitors (the statins) reduces subsequent clinical events on average by $30 \%$ $40 \%{ }^{44-48}$ HMGCoA reductase catalyses the rate limiting enzyme in cholesterol biosynthesis, and drug treatment reduces serum low density lipoprotein (LDL) cholesterol in patients. However, angiographic trials of lipid lowering have indicated that statins produce little if any regression of established lesions ${ }^{49-51}$ but do reduce the appearance on angiograms of "new" lesions. Thus, the evidence suggests that statins may change the characteristics of the plaque to stabilise fragile, moderate sized plaques, with little reduction in plaque volume. Indeed, preliminary evidence suggests that statins increase collagen content and decrease lipid content, inflammation, matrix metalloproteinases, and cell death in human carotid plaques. $^{52}$

Recent studies in animals have confirmed profound differences in plaque characteristics and components in established atherosclerosis after lipid lowering. Cholesterol lowering in rabbits or monkeys reduces macrophage content of plaques, and increases VSMC content, with VSMCs showing markers of a more differentiated phenotype. ${ }^{5-55}$ Lipid lowering also reduces MMP expression and activity in plaques and increases collagen content. ${ }^{56}$

Although many of the beneficial effects of statins may be via reduction in cholesterol, many effects of these drugs appear to be inde-
Vascular smooth muscle cells from atherosclerotic plaques show:

- Poor proliferation after plaque rupture in vivo or in culture

- Higher levels of apoptosis in vivo and spontaneously in culture than cells from normal vessels

- Both of these properties contribute to ineffective plaque repair

pendent of LDL cholesterol lowering. Thus, benefit from statins occurs in low risk patients with relatively "normal" cholesterol levels. ${ }^{46}{ }^{47}$ In addition, administration of pravastatin to lipid fed monkeys at doses that did not reduce cholesterol levels still reduced macrophage content of plaques. ${ }^{57}$ Animal studies with drugs other than statins also show the same changes in plaque composition. ${ }^{58}$

Statins also have potent effects on inflammation, both locally within the plaque and systemically. Statins reduce the macrophage content of atherosclerotic plaques and the activity of the residual macrophage populations, and some statins also reduce serum $\mathrm{C}$ reactive protein and interleukin- 6 in patients, independent of lipid lowering. ${ }^{59-61}$ In addition, statins reduce activity of natural killer cells ${ }^{62}$ and inhibit antibody production. ${ }^{63}$ Statins also inhibit MMP-9 expression of both mouse and human macrophages ${ }^{64}$ and have variable effects on matrix proteins and collagen. ${ }^{65}$ Oxidised LDL induced growth of macrophages and foam cell formation is also inhibited by statins. $^{6667}$

\section{Conclusions}

In summary, we have entered a new phase in the study and treatment of atherosclerosis. Clinically, we aim to improve the stability of established atherosclerotic plaques by reducing both lipid and inflammatory cell contents, indirectly increasing VSMC and collagen contents. Interrupting the cycle of subclinical plaque rupture/erosion and repair also inhibits plaque progression, and reduces the appearance of new lesions. Although the beneficial effects of the statins are salutatory, many patients have clinical events despite optimal treatment of serum cholesterol. There is thus huge scope and requirement for drugs that further reduce the inflammation within plaques to promote stability.

MRB is supported by a British Heart Foundation Senior Fellowship.

1 Falk E, Shah PK, Fuster V. Coronary plaque disruption. Circulation 1995;92:657-71.

2 Davies MJ, Richardson PD, Woolf N, et al. Risk of thrombosis in human atherosclerotic plaques: role of extracellular lipid, macrophage, and smooth muscle cell content. Br Heart F 1993;69:377-81.

3 Bauriedel G, Hutter R, Welsch U, et al. Role of smooth muscle cell death in advanced coronary primary lesions: implications for plaque instability. Cardiovasc Res 1999;41: $480-8$.

4 Weissberg P, Clesham G, Bennett M. Is vascular smooth muscle cell proliferation beneficial? Lancet 1996;347:305-7

muscle cell Proliferation be Libby P. Molect Circulation 1995;91:2844-50.

6 Davies M, Thomas A. Plaque fissuring - the cause of acute myocardial infarction, sudden ischaemic death and cre-
scendo angina. Br Heart $\mathcal{f}$ 1985;53:363. 
7 Gordon D, Reidy MA, Benditt EP, et al. Cell proliferation in human coronary arteries. Proc Natl Acad Sci U S A 1990;87: 4600-4.

8 O'Brien ER, Alpers CE, Stewart DK, et al. Proliferation in primary and restenotic coronary atherectomy tissue. Implications for antiproliferative therapy. Circ Res 1993;73:223-31

9 Lutgens E, de Muinck ED, Kitslaar PJ, et al. Biphasic pattern of cell turnover characterizes the progression from fatty streaks to ruptured human atherosclerotic plaques. Cardiovasc Res 1999;41:473-9.

10 Shi Y, O'Brien J, Fard A, et al. Adventitial myofibroblasts contribute to neointimal formation in injured poricine coronary arteries. Circulation 1996;94:1655-64.

11 Newby AC, Zaltsman AB. Fibrous cap formation or destruction - the critical importance of vascular smooth muscle cell proliferation, migration and matrix formation. Cardiovasc Res 1999;41:345-60.

12 Ross R, Masuda J, Raines EW, et al. Localization of PDGF-B protein in macrophages in all phases of atherogenPis. Science 1990;248:1009-12.

13 Wilson VJ, Ward JP, Burnand KG, et al. Upregulation of IGF-I and collagen I mRNA in human atherosclerotic tissue is not accompanied by changes in type 1 IGF receptor or collagen III mRNA: an in situ hybridization study. Coron Artery Dis 1996;7:569-72.

14 Ross R, Wight TN, Strandness E, et al. Human atheroscleosis. I. Cell constitution and characteristics of advanced lesions of the superficial femoral artery. Am $\mathcal{F}$ Pathol 1984;114:79-93.

15 Bennett MR, Evan GI, Schwartz SM. Apoptosis of human vascular smooth muscle cells derived from normal vessels and coronary atherosclerotic plaques. 7 Clin Invest 1995;95: 2266-74.

16 Orekhov AN, Karpova II, Tertov VV, et al. Cellular composition of atherosclerotic and uninvolved human aortic sition of atherosclerotic and uninvolved human aortic ated aortic cells. Am f Pathol 1984;115:17-24.

17 Orekhov A, Tertov V, Kudryashov S, et al. Primary cultures of human aortic intima cells as a model for testing antiatherosclerotic drugs. Effects of cyclic AMP, prostaglandins, calcium antagonists, antioxidants, and lipid-lowering agents. Atherosclerosis 1986;60:101-10

18 Chung IM, Schwartz SM, Murry CE. Clonal architecture of normal and atherosclerotic aorta-implications for atherogenesis and vascular development. Am F Pathol 1998;152 913-23

19 Han D, Haudenschild C, Hong M, et al. Evidence for apoptosis in human atherosclerosis and in a rat vascular injury model. Am ₹ Pathol 1995;147:267-77.

20 Geng Y, Libby P. Evidence for apoptosis in advanced human atheroma: colocalization with interleukin- $1 \beta$ converting enzyme. Am f Pathol 1995;147:251-66.

21 Isner J, Kearney M, Bortman S, et al. Apoptosis in human atherosclerosis and restenosis. Circulation 1995;91:2703-11.

22 Boyle J, Bennett M, Proudfoot D, et al. Human monocyte/ macrophages induce human vascular smooth muscle cell apoptosis in culture. F Pathol 1998;184:A13 [abstract]

23 Bennett M, Macdonald K, Chan S-W, et al. Cell surface rafficking of Fas: a rapid mechanism of p53-mediated apoptosis. Science 1998;282:290-3.

24 Flynn P, Byrne C, Baglin T, et al. Thrombin generation by apoptotic vascular smooth muscle cells. Blood 1997;89: 4373-84.

25 Bombeli T, Karsan A, Tait JF, et al. Apoptotic vascular endothelial cells become procoagulant. Blood 1997;89: 2429-42.

26 Mallat Z, Benamer H, Hugel B, et al. Elevated plasma levels of shed membrane microparticles in patients with acute coronary syndromes. Circulation 1998;98:I-172 [abstract].

27 Mallat Z, Hugel B, Ohan J, et al. Shed membrane microparticles with procoagulant potential in human atherosclerotic plaques - a role for apoptosis in plaque thrombogenicity

28 Constaninides P. Plaque fissures in human atherosclerotic plaques. F Atheroscl Res 1966;6:1-7.

29 Van der Wal A, Becker A, Vanderloos C, et al. Site of intima rupture or erosion of thrombosed coronary atherosclerotic plaques is characterized by an inflammatory process rrespective of the dominant plaque morphology. Circulation 1994;89:36-44

30 Richardson PD, Davies MJ, Born GV. Influence of plaque configuration and stress distribution on fissuring of coronary atherosclerotic plaques [see comments]. Lancet 1989;ii:941-4.

31 Moreno PR, Falk E, Palacios IF, et al. Macrophage infiltration in acute coronary syndromes. Implications for plaque tion in acute coronary syndromes.
rupture. Circulation 1994;90:775-8.

32 Stary HC. The sequence of cell and matrix changes in atherosclerotic lesions of coronary arteries in the first forty ears of life. Eur Heart f 1990;11 (suppl E):3-19.

33 Tracy RE, Devaney K, Kissling G. Characteristics of the plaque under a coronary thrombus. Virchows Arch A Pathol Anat Histopathol 1985;405:411-27.

34 Isner J, Donaldson R, Fortin A, et al. Attenuation of media of coronary arteries in advanced atherosclerosis. Am 7 Cardiol 1986;58:397.

35 Galis ZS, Sukhova GK, Lark MW, et al. Increased expression of matrix metalloproteinases and matrixdegrading activity in vulnerable regions of human atherosclerotic plaques. 7 Clin Invest 1994;94:2493-503.

36 Galis ZS, Sukhova GK, Kranzhofer R, et al. Macrophage foam cells from experimental atheroma constitutively produce matrix-degrading proteinases. Proc Natl Acad Sci
US A 1995;92:402-6.
37 Galis ZS, Muszynski M, Sukhova GK, et al. Cytokinestimulated human vascular smooth muscle cells synthesize a complement of enzymes required for extracellular matrix digestion. Circ Res 1994;75:181-9.

38 Galis ZS, Sukhova GK, Libby P. Microscopic localization of active proteases by in-situ zymograph-detection of matrix metalloproteinase activity in vascular tissue. FASEB F 1995; 9:974-80.

39 Saren P, Welgus HG, Kovanen PT. TNF-alpha and IL-1beta selectively induce expression of $92-\mathrm{kDa}$ gelatinase by human macrophages. F Immunol 1996;157:4159-65.

40 Schonbeck U, Mach F, Sukhova GK, et al. Regulation of matrix metalloproteinase expression in human vascular smooth muscle cells by T lymphocytes: a role for CD40 signaling in plaque rupture? Circ Res 1997;81:448-54.

41 Mach F, Schonbeck U, Bonnefoy JY, et al. Activation of monocyte/macrophage functions related to acute atheroma complication by ligation of CD40: induction of collagenase, stromelysin, and tissue factor. Circulation 1997;96:396-9.

42 Shah PK, Falk E, Badimon JJ, et al. Human monocytederived macrophages induce collagen breakdown in fibrous caps of atherosclerotic plaques. Potential role of matrixdegrading metalloproteinases and implications for plaque rupture. Circulation 1995;92:1565-9.

43 Mann J, Davies MJ. Mechanisms of progression in native coronary artery disease: role of healed plaque disruption. Heart 1999;82:265-8.

44 4S Group. Randomised trial of cholesterol lowering in 4444 pateints with coronary heart disease: the Scandinavian Sim-

45 Shepherd J, Cobbe S, Isles C. Prevention of coronary heart disease with pravastatin in men with hypercholesterolemia N Engl F Med 1995;333:1301-7.

46 Sacks FM, Pfeffer MA, Moye LA, et al. The effect of pravastatin on coronary events after myocardial infarction in patients with average cholesterol levels. Cholesterol and Recurrent Events Trial Investigators. $N$ Engl $f \mathrm{Med}$ 1996;335:1001-9.

47 Downs JR, Clearfield M, Weis S, et al. Primary prevention of acute coronary events with lovastatin in men and women with average cholesterol levels: results of AFCAPS/ TexCAPS. Air Force/Texas Coronary Atherosclerosis Prevention Study. $\mathscr{F} A M A$ 1998;279:1615-22.

48 LIPID Group. Prevention of cardiovascular events and death with pravastatin in patients with coronary heart disease and a broad range of initial cholesterol levels. $N$ Engl f Med 1998;339:1349-57

49 MAAS Group. Effect of simvastatin on coronary atheroma: the Multicentre Anti-Atheroma Study (MAAS). Lancet 1994;344:633-8.

50 Pitt B, Mancini GB, Ellis SG, et al. Pravastatin limitation of atherosclerosis in the coronary arteries (PLAC I): reduction in atherosclerosis progression and clinical events. PLAC I investigation. F Am Coll Cardiol 1995;26:1133-9.

51 Jukema J, Bruschke A, Van Boven A. Effects of lipid lowering by pravastatin on progression and regression of coronary artery disease in symptomatic men with normal to mdoerately elevated serum cholesterol levels. The Regression Growth Evaluation
Circulation 1995;91:2528-40.

52 Crisby M, Shah P, Yano J, et al. Pravastatin treatment increases collagen content and decreases lipid content, inflammation, matrix metalloproteinases and cell death in human carotid plaques favoring lesion stability. Circulation 1999;100:I-469 [abstract]

53 Hollander W, Colombo M, Faris B, et al. Changes in the connective tissue proteins, glycosaminoglycans and calcium in the arteries of the cynomolgus monkey during atherosclerotic induction and regression. Atherosclerosis 1984;51:89rotic 108 .

54 Shiomi M, Ito $\mathrm{T}$, Tsukada $\mathrm{T}$, et al. Reduction of serum cholesterol levels alters lesional composition of atherosclerotic plaques. Effect of pravastatin sodium on atherosclerosis in mature WHHL rabbits. Arterioscler Thromb Vasc Biol 1995;15:1938-44.

55 Aikawa M, Rabkin E, Voglic SJ, et al. Lipid lowering promotes accumulation of mature smooth muscle cells expressing smooth muscle myosin heavy chain isoforms in rabbit atheroma. Circ Res 1998;83:1015-26.

56 Aikawa M, Rabkin E, Okada Y, et al. Lipid lowering by diet reduces matrix metalloproteinase activity and increases collagen content of rabbit atheroma: a potential mechanism of lesion stabilization. Circulation 1998;97:2433-44.

57 Williams JK, Sukhova GK, Herrington DM, et al. Pravastatin has cholesterol-lowering independent effects on the artery wall of atherosclerotic monkeys. $7 \mathrm{Am}$ Coll Cardiol 31:684-91.

58 Braesen JH, Beisiegel U, Niendorf A. Probucol inhibits not only the progression of atherosclerotic disease, but causes a different composition of atherosclerotic lesions in WHHLrabbits. Virchows Arch 1995;426:179-88.

59 Ridker PM, Rifai N, Pfeffer MA, et al. Inflammation, pravastatin, and the risk of coronary events after myocardial infarction in patients with average cholesterol levels. Cholesterol and Recurrent Events (CARE) Investigators. Circulation 1998;98:839-44.

60 Ridker PM, Rifai N, Pfeffer MA, et al. Long-term effects of pravastatin on plasma concentration of C-reactive protein. The Cholesterol and Recurrent Events (CARE) Investigators. Circulation 1999;100:230-5.

61 Rosenson RS, Tangney CC, Casey LC. Inhibition of proinflammatory cytokine production by pravastatin [letter].
Lancet $1999 ; 353: 983-4$. 
62 Katznelson S, Wang XM, Chia D, et al. The inhibitory effects of pravastatin on natural killer cell activity in vivo and on cytotoxic T lymphocyte activity in vitro. $\mathcal{f}$ Heart Lung Transplant 1998;17:335-40.

63 Kimura T, Shinkai K, Masuda H, et al. Influence on HMGCOA reductase inhibitors on plaque-forming cell (PFC) response in mice. F Toxicol Sci 1995;20:603-8.

64 Bellosta S, Via D, Canavesi M, et al. HMG-CoA reductase inhibitors reduce MMP-9 secretion by macrophages. Arterioscler Thromb Vasc Biol 1998;18:1671-8.
65 Nogaki F, Muso E, Yashiro M, et al. Direct inhibitory effects of simvastatin on matrix accumulation in cultured murine mesangial cells. Kidney Int Suppl 1999;71:S198-201.

66 Bernini F, Scurati N, Bonfadini G, et al. HMG-CoA reductase inhibitors reduce acetyl LDL endocytosis in mouse peritoneal macrophages. Arterioscler Thromb Vasc Biol 1995; 15:1352-8

67 Sakai M, Kobori S, Matsumura T, et al. HMG-CoA reductase inhibitors suppress macrophage growth induced by oxidized low density lipoprotein. Atherosclerosis 1997;133:51-9.

\section{IMAGES IN MEDICINE}

\section{Auto-TIPS}

A 54 year old man with Child's C liver cirrhosis resulting from alcohol abuse presented with pleuritic right upper quadrant abdominal pain. $\mathrm{He}$ did not have ascites or any history of gastrointestinal bleeding. On examination, his liver was palpable $4 \mathrm{~cm}$ below the costal margin and was lobular and non-tender. Abdominal ultrasound revealed a mass in the right lobe of the liver (later proved by biopsy to be a hepatoma) as well as a shunt on Doppler study. Magnetic resonance angiography of the liver (fig 1) revealed a shunt (S) between the portal vein (PV) and the hepatic vein (HV) which is seen joining the right atrium (RA) leading to the inferior vena cava (IVC). On further questioning, the patient admitted being stabbed in the right upper quadrant 20 years ago.

The majority of the patients with Child's C cirrhosis have complications like ascites or gastrointestinal bleeding caused by portal hypertension. The trauma experienced by our patient resulted in formation of a transcutaneous intrahepatic portocaval shunt or "autoTIPS" (transjugular intrahepatic portosystemic shunt) which prevented the development of portal hypertension.

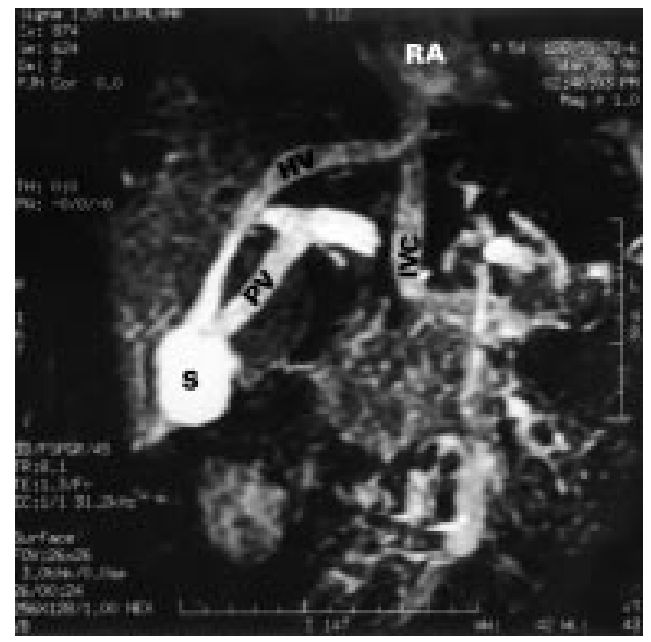

Figure 1 Magnetic resonance angiogram of the liver. 